\title{
Phenolic Composition and Sensory Properties of Ciders Produced from Latvian Apples
}

\author{
Rita Riekstina-Dolge $^{1 *}$, Zanda Kruma ${ }^{1}$, Fredijs Dimins ${ }^{2}$, Evita Straumite ${ }^{1}$, Daina Karklina ${ }^{1}$ \\ ${ }^{1}$ Department of Food Technology, LLU, Liela iela 2, Jelgava LV-3001, Latvia \\ ${ }^{2}$ Department of Chemistry, LLU, Liela iela 2, Jelgava LV-3001, Latvia
}

\begin{abstract}
Polyphenol compounds are very important components of cider - they are responsible for the colour and the bitterness and astringency balance of cider. The polyphenolic profile of apples and apple drinks is influenced by several factors: apple variety, climate, maturity, and technological processes applied. This research paper concerns the influence of apple variety on the phenolic compounds and sensory properties of cider. Fermentation of 12 varieties of apple juice with Saccharomyces cerevisiae yeast '71B-1122' (Lalvin, Canada) was performed in a laboratory of the Faculty of Food Technology of the Latvia University of Agriculture. The total phenol content (TPC) was determined according to the Folin-Ciocalteu spectrophotometric method. Individual phenolic compounds were analysed using HPLC. Sensory properties (clarity, the apple, fruit and yeast aroma, the apple and yeast taste, sourness, astringency, and bitterness) were evaluated by trained panelists using a line scale. Special attention was paid to the use of dessert apples for the production of cider. The most important sensory properties of cider are the aroma and taste of apples and fruit. All cider samples showed the intensity of apple aroma ranging from 5.3 to 7.6 points, and higher results were obtained for cider from the variety 'Auksis' apples. The TPC in cider samples varied from 792.68 to $3399.78 \mathrm{mg} \mathrm{L}^{-1}$ : Among crab apples, the highest TPC was detected in ciders made from the 'Hyslop' and 'Riku' varieties, whereas among dessert apples, the highest TPC was detected in ciders made from the 'Antonovka' variety. Among the twelve phenols identified in cider samples, chlorogenic acid and caffeic acid were the dominating ones. Variation in the sensory properties of ciders was dependent on the physicochemical composition of the apples used.
\end{abstract}

Key words: Apple variety, cider, phenolic compounds, sensory properties.

\section{Introduction}

Cider is a fermented drink obtained from apple juice. Apples are an excellent source of several phenolic compounds and also possess a high total antioxidant capacity (Sun, Chu, Wu, \& Liu, 2002). The researchers have found that apples had the highest content of soluble free phenolics when compared to 10 other commonly consumed fruits (Vinson, Su, Zubik, \& Bose, 2001). Apples contain a variety of phenolic compounds that can be classified into several sub-classes with procyanidins being the most abundant class (between $40 \%$ and $89 \%$ ), followed by hydroxycinnamic acids, dihydrochalcones, flavonols, anthocyanins, and flavan-3-ols (Alonso-Salces et al., 2004; Tsao, Yang, Young, \& Zhu, 2003). The content and composition of polyphenols present in apples are important because of their contribution to the sensory quality of fresh fruit and processed apple products. For cider production, the content and profile of polyphenols are an important quality indicator since they contribute to the colour, bitterness, and astringency, which provide the mouth-feel of cider (Alonso-Salces et al., 2004; Lea \& Drilleau, 2003). Some polyphenols such as hydroxycinnamic acids are the precursors of volatile compounds that contribute to cider aroma (Lea, 1995). The polyphenolic profile of apples and apple drinks is also influenced by several factors: variety, climate, maturity, storage, and processing (Lata, 2007; Ruiz-Rodriguez, Marin, Ocana, \& Soler-Rivas, 2008; Van der Sluis, Dekker, De Jager, \& Jongen, 2001). Phenolics have been used for detecting adulterations in apple products and could be inhibitors for microbiological growth-avoiding process spoilages (Madrera, Lobo, \& Valles, 2006). But the most recent investigations show that, for example, by manipulating the pressing conditions of apple juice, the bitterness and astringency decreased much less than in the concentrations of native polyphenols (Renard et al., 2011).

\footnotetext{
* Corresponding author's email:

Rita.Riekstina@1lu.lv
}

(C) Latvia University of Agriculture (LLU) 2014 
Not all ciders are made from "true" cider apples. Many modern ciders have a high proportion of dessert apple varieties (Lea, 1995). The cidermaking steps mainly responsible for the extraction and content of the phenols in the final product are maceration, pressing, enzymatic clarification of the must prior to fermentation, centrifugation, filtration, and fining. The enzymatic clarification, centrifugation, filtration and fining of French ciders lead to the partial elimination of procyanidins due to their ability to precipitate proteins and to interact with cell-wall polysaccharides (Alonso-Salces et al., 2004). For the development of the quality of ciders produced from Latvian apples, it is important to investigate the phenolic composition of ciders from different apple varieties in order to develop fermented apple drinks with potentially the best sensory properties. Up to now, no detailed studies of apples suitable for cider production have been carried out in Latvia. In the present research, phenolic composition and sensory properties of ciders were evaluated with the aim to choose the apple varieties most suitable for cider production.

\section{Materials and Methods \\ Raw material}

In the experiment, 12 varieties of apples grown at the Latvia State Institute of Fruit Growing and at the Pure Horticultural Research Centre were used:

- dessert apple varieties 'Auksis', 'Lietuvas Pepins', 'DI-93-4-14', 'Remo', 'Antonovka', and 'Merrigold';

- crab apple varieties 'Riku', 'Ruti', 'K-8/9-24', 'Cornelie', 'Hyslop', and 'Kuku'.
Apples were harvested in September and October 2011. Juice was obtained by the mechanical press Voran Basket Press 60K (Voran Maschinen $\mathrm{GmbH}$, Austria). For stabilization of the juice before fermentation, Tannisol (Enartis, Italy) was added. Tannisol tablets contain potassium metabisulphite (95\%), ascorbic acid (0.3\%) and tannin $(0.2 \%)$, and the amount added to juice was $0.1 \mathrm{~g} \mathrm{~L}^{-1}$.

\section{Fermentation conditions}

Fermentation was performed using the commercial Saccharomyces cerevisiae yeast '71B1122' (Lalvin, Lallemand Inc., Canada) at $16 \pm 1{ }^{\circ} \mathrm{C}$ for 28 days. The apple juice obtained was fermented in glass bottles (for each cider type $n=5$ ) with a volume of $750 \mathrm{~mL}$. For analysis, the average cider samples were combined in equal proportions from the five bottles.

\section{Chemical composition of cider}

Determination of titratable acidity was performed according to the method LVS EN 12147:2001 and was expressed in $\mathrm{g} \mathrm{L}^{-1}$. The content of soluble solids was determined by the method LVS EN 12143:2001 and expressed in Brix $^{\circ}$ (one degree of Brix is one gram of sucrose in 100 grams of a solution). Alcohol content was determined by volume \% (ГОСТ 12787-81), and relative density was determined according to LVS EN 1131:2001 and expressed in $\mathrm{g} \mathrm{L}^{-1}$.

Sensory properties of cider depend on its physicochemical composition; quality parameters of the analysed samples are given in Table 1.

Table 1

Chemical and physical parameters of apple cider

\begin{tabular}{lcccc}
\hline \multicolumn{1}{c}{ Apple variety } & Titratable acidity, $\mathrm{g} \mathrm{L}^{-1}$ & Ethanol content, $\% \mathrm{v} / \mathrm{v}$ & Brix, \% & Density, $\mathrm{g} \mathrm{mL}^{-1}$ \\
\hline 'Cornelie' & $9.49 \pm 0.47$ & $7.67 \pm 0.28$ & $3.21 \pm 0.12$ & $1.0107 \pm 0.0374$ \\
\hline 'Hyslop' & $10.75 \pm 0.54$ & $6.16 \pm 0.24$ & $1.95 \pm 0.07$ & $1.0058 \pm 0.0335$ \\
\hline K-8/9-24 & $10.69 \pm 0.53$ & $5.88 \pm 0.21$ & $1.57 \pm 0.06$ & $1.0043 \pm 0.0359$ \\
\hline 'Kuku' & $8.31 \pm 0.42$ & $7.73 \pm 0.29$ & $3.68 \pm 0.13$ & $1.0126 \pm 0.0349$ \\
\hline 'Antonovka' & $10.83 \pm 0.54$ & $4.70 \pm 0.22$ & $3.81 \pm 0.14$ & $1.0017 \pm 0.0371$ \\
\hline 'Riku' & $11.98 \pm 0.60$ & $7.50 \pm 0.28$ & $2.77 \pm 0.09$ & $1.0090 \pm 0.0336$ \\
\hline 'Lietuvas Pepins' & $10.45 \pm 0.52$ & $5.61 \pm 0.22$ & $0.69 \pm 0.03$ & $1.0009 \pm 0.0371$ \\
\hline 'Merrigold' & $6.78 \pm 0.34$ & $6.70 \pm 0.26$ & $0.54 \pm 0.02$ & $0.9968 \pm 0.0369$ \\
\hline 'Auksis' & $6.27 \pm 0.31$ & $5.55 \pm 0.20$ & $0.53 \pm 0.02$ & $0.9967 \pm 0.0311$ \\
\hline 'Ruti' & $8.74 \pm 0.44$ & $6.74 \pm 0.34$ & $2.23 \pm 0.08$ & $1.0069 \pm 0.0373$ \\
\hline 'Remo' & $13.37 \pm 0.67$ & $6.25 \pm 0.26$ & $0.82 \pm 0.02$ & $1.0013 \pm 0.0303$ \\
\hline DI-93-4-14 & $9.67 \pm 0.48$ & $6.34 \pm 0.30$ & $0.63 \pm 0.02$ & $0.9981 \pm 0.0371$ \\
\hline
\end{tabular}


The total phenolic concentration was determined spectrophotometrically according to the FolinCiocalteu colorimetric method (Singleton, 1999). The fermented apple juice was diluted with ethanol/ acetic acid solution $(1: 20 \mathrm{v} / \mathrm{v})$. The ethanol/acetic acid solution was prepared using an acetic acid water solution (2.5\%) and ethanol (98\% vol.) in the ratio of 10:90 (v/v). To $0.5 \mathrm{~mL}$ of aliquot, $2.5 \mathrm{~mL}$ of Folin-Ciocalteu reagent (diluted 10 times with water) were added, and after 3 minutes, also $2 \mathrm{~mL}$ of sodium carbonate $\left(\mathrm{Na}_{2} \mathrm{CO}_{3}\right)\left(75 \mathrm{~g} \mathrm{~L}^{-1}\right)$ were added. After 30 minutes of incubation at room temperature, the absorbance was measured at $765 \mathrm{~nm}$ using a JENWAY 6300 spectrophotometer (Barloworld Scientific Ltd., UK).

The concentration of all individual polyphenols was determined by high-performance liquid chromatography (HPLC) using Shimadzu LC-20AD Prominence with a diode array detector (SPDM20A)._Separation was performed in a PerkinElmer C18 4.6 $\times 250-\mathrm{mm}$ column (thermostated at $27^{\circ} \mathrm{C}$ ). Eluting solvents were methanol (A, 20\%), water (B, 78.4\%), and acetic acid $(\mathrm{C}, 1.6 \%)$ used in a gradient mode. At the 17.50 th minute, the ratio of solvents was: $\mathrm{A}-40.3 \%, \mathrm{~B}-58.5 \%$, and $\mathrm{C}-1.2 \%$. A total of $10 \mu \mathrm{L}$ of each sample were injected in the chromatograph using an automatic sample injection system SIL-20 AC. The total duration of analysis was 35 minutes. For detection and quantification of compounds, several wavelengths were used: $253 \mathrm{~nm}$ for 4-hydroxybenzoic acid and rutine, $263 \mathrm{~nm}$ for gallic acid, $278 \mathrm{~nm}$ for catechin, caffeic acid and syringic acid, and $298 \mathrm{~nm}$ for chlorogenic acid, epicatechin, coumaric acid, sinapic acid and ferulic acid.

The phenolic compounds were tentatively identified according to their order of elution and retention times of standard compounds. The method was developed at the Department of Chemistry of the Latvia University of Agriculture (LLU) based on the recommendations of the company Shimadzu.

\section{Sensory analysis}

Sensory evaluation of cider samples was carried out by trained panelists (19 women and 5 men, age 21-64). The panelists had studied the basics of sensory evaluation methods and were experienced in sensory panels. The group included the students and staff of the Faculty of Food Technology of LLU. For determination of the intensity of sensory properties (clarity, the apple, fruit and yeast aroma, and the apple, yeast, sour, astringent and bitter taste), a line scale (ISO 4121:2003) was used.

\section{Statistical analysis}

The analysis of variance was performed by the ANOVA procedure, and $p<0.05$ was considered statistically significant. The linear correlation analysis was performed in order to determine the relationship among sensory properties and among sensory properties and chemical parameters.

\section{Results and Discussion \\ Total phenolic compounds (TPC)}

The content of total phenols in ciders varied from 792.68 to $3399.78 \mathrm{mg} \mathrm{L}^{-1}$ depending on the used apple variety. In ciders made from crab apples, the highest TPC was detected for the 'Hyslop' and 'Riku' varieties, whereas in ciders from dessert apples, the highest TPC was detected for the 'Antonovka' variety, the lowest TPC - for the DI-93-4-14 apples (Fig. 1). These results are in accordance with Nogueira et al. (2008) who reported polyphenol concentrations ranging from 734 to $2463 \mathrm{mg} \mathrm{L}^{-1}$ in apple wine. In a study by AlonsoSalces et al. in 2006, polyphenol concentrations reached $217 \mathrm{mg} \mathrm{L}^{-1}$ in ciders from French apples, and varied from 21 to $512 \mathrm{mg} \mathrm{L}^{-1}$ in ciders from Galician apples. In 2005, in another study, AlonsoSalces et al. had observed the total polyphenol content in Basque ciders of 200-1200 mg of epicatechin equivalent (EC) $\mathrm{L}^{-1}$, which is approximately one-half of the polyphenol content in French ciders (300-3800 mg EC L-1).

\section{Individual phenolic compounds}

In the analysed cider samples, 12 polyphenols were identified, of which the dominating was chlorogenic acid, followed by caffeic acid, catechin, syringic acid, and epicatechin (Table 2).

Chlorogenic acid was the dominant polyphenol in all cider samples, and it ranged from 136.52 to $435.69 \mathrm{mg} \mathrm{L}^{-1}$. The distribution of phenolic acids may strongly vary with the species, variety, and physiological stage (Macheix, Sapis, \& Fleuriet, 1991). Kahle, Kraus, and Richling (2005) reported that hydroxycinnamic acids, with chlorogenic acid as the dominating constituent, ranged from 57 to $68 \mathrm{mg} \mathrm{L}^{-1}$ in dessert apple juices and from 134 to $593 \mathrm{mg} \mathrm{L}^{-1}$ in cider apple juices. Phenolic acids and their derivatives are widely present in plants (vegetables, fruits, grains, and spices), many being 


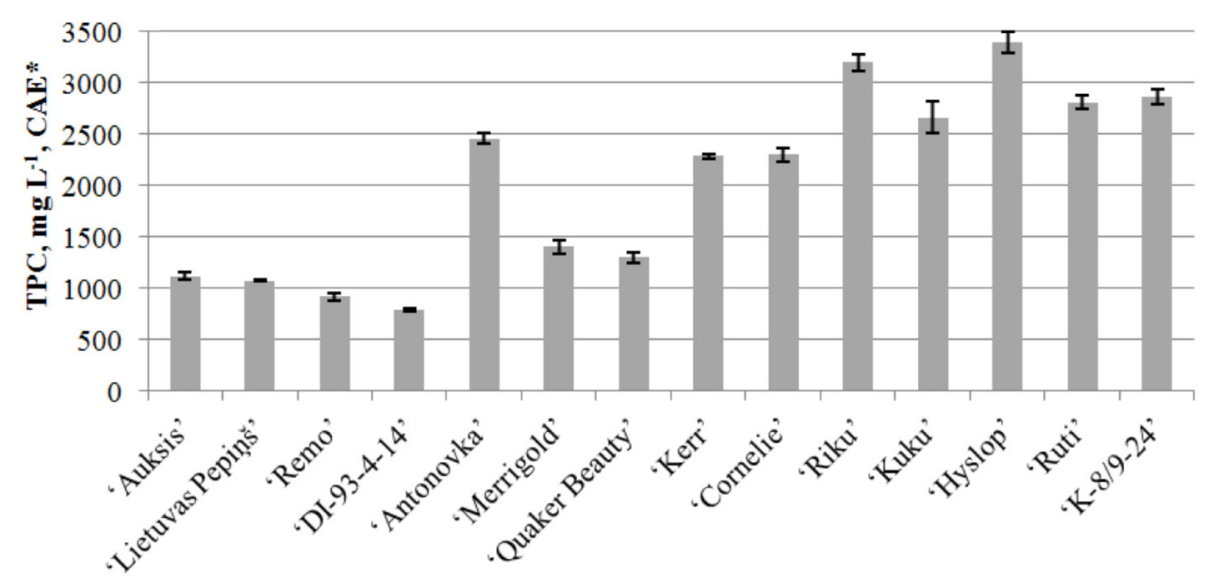

Apple varieties

* - CAE - chlorogenic acid equivalents

Note. In the figure, mean values and standard deviation are presented.

Fig. 1. The content of total phenols in apple cider samples.

The main phenolic compounds in apple cider samples, $\mathrm{mg} \mathrm{L}^{-1}$

Table 2

\begin{tabular}{lccccc}
\hline \multicolumn{1}{c}{ Apple variety } & Catechin & Caffeic acid & Syringic acid & Chlorogenic acid & Epicatechin \\
\hline 'Cornelli' & $3.15 \pm 0.14^{\mathrm{b}}$ & $0.36 \pm 0.02^{\mathrm{a}}$ & $4.75 \pm 0.18^{\mathrm{e}}$ & $233.99 \pm 10.17^{\mathrm{f}}$ & $0.77 \pm 0.03^{\mathrm{b}}$ \\
\hline 'Hyslop' & $5.70 \pm 0.20^{\mathrm{d}}$ & $5.67 \pm 0.20^{\mathrm{c}}$ & $5.14 \pm 0.17^{\text {ef }}$ & $411.61 \pm 19.60^{\mathrm{h}}$ & $7.72 \pm 0.30^{\mathrm{a}}$ \\
\hline 'K-8/9-24' & $10.18 \pm 0.51^{\mathrm{g}}$ & $55.84 \pm 1.99^{\mathrm{j}}$ & $0.82 \pm 0.03^{\mathrm{a}}$ & $221.81 \pm 10.56^{\mathrm{ef}}$ & $0.97 \pm 0.03^{\mathrm{c}}$ \\
\hline 'Kuku' & $4.62 \pm 0.16^{\mathrm{c}}$ & $8.68 \pm 0.35^{\mathrm{d}}$ & $0.97 \pm 0.04^{\mathrm{b}}$ & $210.93 \pm 7.03^{\mathrm{e}}$ & $0.48 \pm 0.02^{\mathrm{a}}$ \\
\hline 'Antonovka' & $8.63 \pm 0.30^{\mathrm{f}}$ & $43.53 \pm 1.98^{\mathrm{i}}$ & $19.18 \pm 0.69^{\mathrm{h}}$ & $273.70 \pm 12.44^{\mathrm{g}}$ & $8.63 \pm 0.30^{\mathrm{j}}$ \\
\hline 'Riku' & $11.92 \pm 0.52^{\mathrm{h}}$ & $8.68 \pm 0.35^{\mathrm{d}}$ & $2.21 \pm 0.08^{\mathrm{d}}$ & $136.52 \pm 1.52^{\mathrm{a}}$ & $2.21 \pm 0.11^{\mathrm{e}}$ \\
\hline 'Lietuvas Pepins' & $6.84 \pm 0.31^{\mathrm{e}}$ & $1.34 \pm 0.04^{\mathrm{b}}$ & $5.20 \pm 0.19^{\mathrm{f}}$ & $435.69 \pm 15.56^{\mathrm{h}}$ & $0.78 \pm 0.04^{\mathrm{b}}$ \\
\hline 'Merrigold' & $14.12 \pm 0.50^{\mathrm{i}}$ & $14.45 \pm 0.54^{\mathrm{f}}$ & $58.99 \pm 2.03^{\mathrm{i}}$ & $142.51 \pm 4.75^{\mathrm{c}}$ & $29.54 \pm 1.06^{\mathrm{k}}$ \\
\hline 'Auksis' & $2.81 \pm 0.10^{\mathrm{a}}$ & $17.48 \pm 0.70^{\mathrm{h}}$ & $1.17 \pm 0.04^{\mathrm{c}}$ & $143.46 \pm 5.74^{\mathrm{c}}$ & $3.37 \pm 0.17^{\mathrm{g}}$ \\
\hline 'Ruti' & $10.70 \pm 0.36^{\mathrm{h}}$ & $15.48 \pm 0.21^{\mathrm{g}}$ & $2.13 \pm 0.09^{\mathrm{d}}$ & $185.12 \pm 9.26^{\mathrm{d}}$ & $2.79 \pm 0.10^{\mathrm{f}}$ \\
\hline 'Remo' & $4.90 \pm 0.21^{\mathrm{c}}$ & $14.17 \pm 0.43^{\mathrm{f}}$ & $11.91 \pm 0.40^{\mathrm{g}}$ & $263.52 \pm 9.09^{\mathrm{g}}$ & $6.15 \pm 0.24^{\mathrm{h}}$ \\
\hline 'DI-93-4-14' & $7.50 \pm 0.38^{\mathrm{e}}$ & $11.23 \pm 0.42^{\mathrm{e}}$ & $0.96 \pm 0.03^{\mathrm{b}}$ & $170.28 \pm 2.51^{\mathrm{b}}$ & $1.57 \pm 0.06^{\mathrm{d}}$ \\
\hline
\end{tabular}

metabolites, and several functions being attributed to them (Stratil, Klejdus, \& Kuban, 2007). Phenolic acids may contribute to the dark colour, bitter taste, and objectionable flavour of some fruits, leaves and seeds, and have been implicated as a possible agent that influences the toxicological, nutritional, sensory, and antioxidant properties of different food products such as fruit juices, wines, and ciders (Macheix, Sapis, \& Fleuriet, 1991). The role of phenolic acids in the bitterness of fruit and fruit products is still a matter of discussion, but it has been concluded that hydroxycinnamic acids do not play any role in the taste of wines even at high concentrations of caftaric acid and glutathionylcaftaric acid
(Macheix, Sapis, \& Fleuriet, 1991). In contrast to other phenolic compounds, hydroxybenzoic acids and hydroxycinnamic acids present an acidic character because of the presence of one carboxylic group in the molecule (Macheix, Sapis, \& Fleuriet, 1991).

Generally, in our research, the phenolic compounds found in the analysed ciders varied, and also other scientists have reported that the proportion of the polyphenol classes varied greatly from one variety to another (Alonso-Salces et al., 2004; Sanoner, Guyot, Marnet, Molle, Drilleau, 1999). Bitter apple varieties have a higher content of flavan-3-ols and/or dihydrochalcones than 
non-bitter varieties. Detailed knowledge of the polyphenolic profile of each apple variety affords information about their susceptibility to oxidation, their sensory properties (bitterness, astringency), and their possible influence on the characteristics and quality of the final product (juice, cider) (Alonso-Salces et al., 2004).

\section{Sensory analysis}

The results of the sensory evaluation of different attributes (namely, clarity, the apple, fruit and yeast aroma, the apple and yeast taste, sourness, astringency, and bitterness) are presented in Fig. 2.
According to ANOVA, the apple variety was significant $(p<0.05)$ for all sensory properties of cider. The most important sensory properties of ciders are the apple and fruit aroma and taste, which depend on the quality of the product. All cider samples showed the intensity of apple aroma from 5.3 to 7.6 points. The panelists' evaluations showed that there were significant differences $(p<0.05)$ among the samples in the intensity of the apple and fruit aroma, and the best results were obtained for cider from the 'Auksis' apples.

The apple aroma strongly negatively $(\mathrm{r}=-0.83)$ correlated with yeast taste and moderately negatively

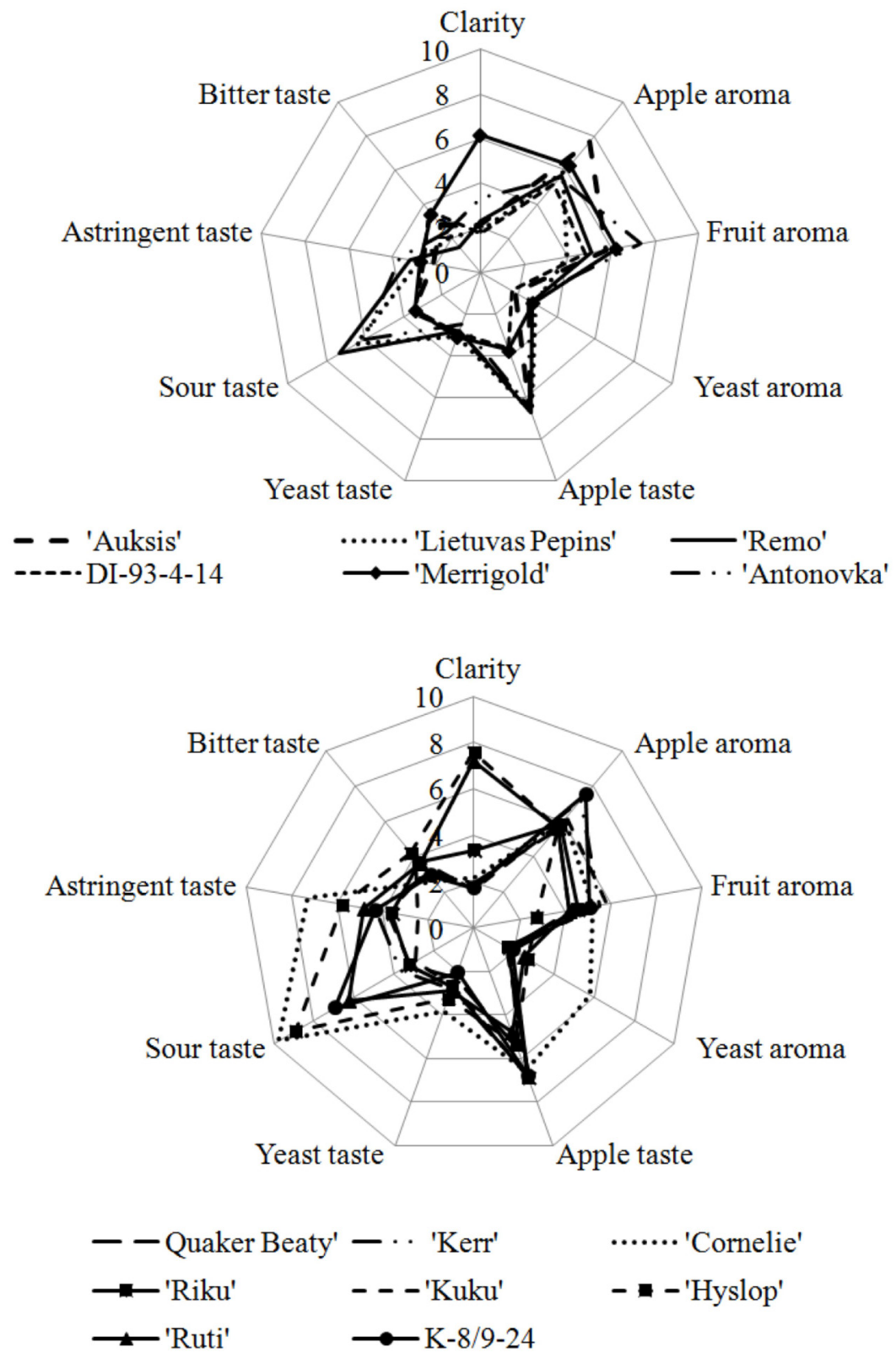

Fig. 2. Spider plot for sensory properties of apple cider samples. 
$(\mathrm{r}=-0.60)$ with yeast aroma. Also the apple aroma and taste moderately positively correlated with sour taste $(r=0.56$ and $r=0.52$, respectively). The intensity of the yeast taste and aroma for all cider samples was not high. According to the assessment of the trained panelists, there was a significant difference $(p<0.05)$ in the intensity of the sour taste among the cider samples. The highest intensity of sour taste was detected in ciders from the 'Cornelie' and 'Hyslop' varieties, and the lowest intensity was detected in ciders from the DI-93-4-14, 'Kuku', 'Merrigold' and 'Auksis' varieties. The sour taste moderately correlated $(\mathrm{r}=0.63)$ with titratable acidity. There were significant differences $(p<0.05)$ in terms of bitterness and astringency among the analysed samples, and the highest intensity of these attributes was in ciders from the 'Riku' and 'Hyslop' crab apple varieties. Comparison of sensory properties and the content of phenolic compounds showed that apple aroma correlated moderately with 4-hidroxybenzoic acid $(\mathrm{r}=0.52)$, vaniline $(\mathrm{r}=0.77)$, sinapic acid $(\mathrm{r}=0.60)$, and ferulic acid $(\mathrm{r}=0.55)$. Fruit aroma correlated moderately negatively with such polyphenols as catechin $(\mathrm{r}=-0.75)$, caffeic acid $(\mathrm{r}=-0.65)$, and epicatechin $(r=-0.63)$.

The importance of phenolic acids in fruit aroma is low; however, many simple aromatic phenols may be released by enzymatic or chemical reactions from glycosylated precursors during maturation or processing, e.g. in vanilla, passion fruit, mango, and apricot (Crouzet, Sakho, \& Chassagne, 1997). Such transformations are also at the origin of some aroma constituents in wines, ciders, and fruit juices through the degradation of hydroxycinnamic acid conjugates. Vanillic acid participates, in addition to vanillin, in vanilla aroma, and cinnamaldehyde is the principal component of cinnamon flavour (Friedman, Kozukue, \& Harden, 2000). Ferulic acid is a potential precursor of off-flavours in a stored citrus juice, and pasteurization increases both the release of free ferulic acid from bound forms and the formation of p-vinyl guaiacol (Naim, Zehavi, Nagy, \& Rouseff, 1992).

\section{Conclusion}

This work is a study on the phenolic composition and sensory attributes of ciders produced from twelve apple varieties grown in Latvia. The highest TPC rates were detected in crab apple varieties. Chlorogenic acid and caffeic acid were the dominating polyphenols in all cider samples. Variation in the sensory properties of ciders was dependent on the physicochemical composition of the apples used. The research results help to understand the principles of selecting apple varieties for the production of cider. For development of a qualitative product, it is necessary to choose varieties with an intensive apple aroma (such as 'Auksis') and a moderate astringency (such as 'Riku' and 'Hyslop').

\section{References}

1. Alonso-Salces, R.M., Barranco, A., Abad, B., Berrueta, L.A., Gallo, B., \& Vicente, F. (2004). Polyphenolic profiles of basque cider apples cultivars and their technological properties. Journal of Agricultural and Food Chemistry, 52(10), 2938-2952. DOI: $10.1021 / \mathrm{j} f 035416 \mathrm{l}$

2. Alonso-Salces, R.M., Guyot, S., Herrero, C., Berrueta, L.A., Drilleau, J.F., Gallo, B., \& Vicente, F. (2005). Chemometric classification of Basque and French ciders based on their total polyphenol contents and CIELab parameters. Food Chemistry, 91(1), 91-98. DOI:10.1016/j.foodchem.2004.05.049

3. Alonso-Salces, R.M., Herrero, C., Barranco, A., López-Márquez, D.M., Berrueta, L.A., Gallo, B., \& Vicente, F. (2006). Polyphenolic compositions of Basque natural ciders: A chemometric study. Food Chemistry, 97, 438446. DOI:10.1016/j.foodchem.2005.05.022

4. Crouzet, J., Sakho, M., \& Chassagne D. (1997). Fruit aroma precursors with special reference to phenolics. In F.A. Tomas-Barberan \& R.J. Robins (Eds.), Proceedings of the Phytochemical Society of Europe: Phytochemistry of Fruit and Vegetables (pp. 109-123). Oxford: Clarendon Press. Retrieved from http://www.crcnetbase. com/doi/book/10.1201/9780203508732. DOI: $10.1201 / 9780203508732 . \operatorname{ch} 10$

5. Friedman, M., Kozukue, N., \& Harden, L.A. (2000). Cinnamaldehyde content in foods determined by gas chromatography-mass spectrometry. Journal of Agriculture and Food Chemistry, 48 (11), 5702-5709. DOI: 10.1021/ jf000585g

6. Kahle, K., Kraus, M., \& Richling, E. (2005). Polyphenol profiles of apple juices. Molecular Nutrition \& Food Research, 49(8), 797-806. DOI 10.1002/mnfr.200500064

7. Lata, B. (2007). Relationship between apple peel and the whole fruit antioxidant content: year and cultivar variation. Journal of 
Agriculture and Food Chemistry, 55(3), 663-671._DOI: 10.1021/jf062664j

8. Lea, A.G.H. (1995). Cidermaking. In A.G.H. Lea \& J.R. Piggott (Eds.), Fermented Beverage Production, (pp. 66-96). London: Chapman \& Hall.

9. Lea, A.G.H., \& Drilleau J. F. (2003). Fermented Beverage Production. New York: Kluver Academic/Plenum.

10. Macheix, J.J., Sapis, J.C., \& Fleuriet, A. (1991). Phenolic compounds and polyphenoloxidase in relation to browning in grapes and wines. Critical Reviews in Food Science and Nutrition, 30 (4), 441-486. DOI: 10.1080/ 1040839910952755

11. Madrera, R.R., Lobo, A.P., \& Valles, B.S. (2006). Phenolic profile of Asturian (Spain) natural cider. Journal of Agriculture and Food Chemistry, 54(1), 120-124. DOI: 10.1021/ jf051717e

12. Naim, M., Zehavi, U., Nagy, S., \& Rouseff, R.L. (1992). Hydroxycinnamic acids as offflavor precursors in citrus fruits and their products. In Phenolic Compounds in Food and Their Effects on Health. I. Analysis, Occurrence, and Chemistry (pp. 180-191). Washington: American Chemical Society. DOI: 10.1021/bk-1992-0506.ch014

13. Nogueira, A., Guyot, S., Marnet, N., Luquere, J.M., Drilleau, J.F., \& Wosiaki G. (2008). Effect of alcoholic fermentation in the content of phenolic compounds in cider processing. Brazilian Archives of Biology and Technology, 51(5), 1025-1032.

14. Renard, C.M.G., Le Quéré, J.M., Bauduin, R., Symoneaux, R., Le Bourvellec, C. \& Baron, A. (2011). Modulating polyphenolic composition and organoleptic properties of apple juices by manipulating the pressing conditions. Food Chemistry, 124 (1), 117-125. DOI: 10.1016/j.foodchem.2010.05.113

15. Ruiz-Rodriguez, A., Marin, F.R., Ocana, A., \& Soler-Rivas, C. (2008). Effect of domestic processing on bioactive compounds. Phytochemistry Reviews, 7, 345-384. DOI 10.1007/s11101-007-9073-1

16. Sanoner, P., Guyot, S., Marnet, N., Molle, D., \& Drilleau, J.P. (1999). Polyphenol profiles of French cider apple varieties (Malus domestica sp.). Journal of Agricultural and Food Chemistry, 47(12), 4847-4853. DOI: $10.1021 / \mathrm{j} 9990563 \mathrm{y}$

17. Singleton, V.L., Orthofer, R., \& Lamuela-Raventos, R.M. (1999). Analysis of total phenols and other oxidation substrates and antioxidants by means of FolinCiocalteu reagent. Methods in Enzymology, $29,152-178$.

18. Stratil, P., Klejdus, B., \& Kuban, V. (2007). Determination of phenolic compounds and their antioxidant activity in fruits and cereals. Talanta, 71(4), 1741-1751. DOI: 10.1016/j. talanta.2006.08.012

19. Sun, J., Chu, Y.F., Wu, X., \& Liu, R.H. (2002). Antioxidant and antiproliferative activities of common fruits. Journal of Agricultural and Food Chemistry, 50(25), 7449-7454. DOI: $10.1021 / \mathrm{jf0207530}$

20. Tsao, R., Yang, R., Young, J.C., \& Zhu, H. (2003). Polyphenolic profiles in eight apple cultivars using high-performance liquid chromatography (HPLC). Journal of Agricultural and Food Chemistry, 51(21), 6347-6353. DOI: 10.1021/jf0346298

21. Van der Sluis, A.A., Dekker, M., De Jager, A., Jongen, W.M.F. (2001). Activity and concentration of polyphenolic antioxidants in apple: effect of cultivar, harvest year, and storage conditions. Agriculture and Food Chemistry, 49(8), 3606-3613. DOI: $10.1021 / \mathrm{jf001493 \textrm {u }}$

22. Vinson, J.A., Su, X., Zubik, L., \& Bose, P. (2001). Phenol antioxidant quantity and quality in foods: fruits. Journal of Agricultural and Food Chemistry, 49(11), 5315-5321. DOI: $10.1021 / \mathrm{jf0009293}$

\section{Acknowledgement}

The research has been done within the State Research Programme "Sustainable Use of Local Resources (Entrails of the Earth, Forest, Food and Transport) - New Products and Technologies (NatRes)" (2010-2013), project No. 3 „Sustainable use of local agricultural resources for development of high nutritive value food products (Food)", and ESF project "Support for the implementation of LLU doctoral studies", contract No. 2009/0180/1DP/1.1.2.1.2/09/IPIA/VIAA/017. The authors also acknowledge the Latvia State Institute of Fruit Growing and the Pure Horticultural Research Centre for the supply of apples. 